\title{
Research on Clinical Decisions Made Daily in Family Medicine
}

\author{
Marjorie A. Bowman, MD, MPA, Anne Victoria Neale, PhD, MPH, and \\ Dean A. Seehusen, $M D, M P H$
}

This issue presents research on the types of decisions that are required daily in family medicine. Patients often make these health decisions, and family physicians help patients with these decisions daily. Patients and their family physicians discuss when to quit screening for colon cancer, which treatment to choose for localized prostate cancer, when to test for pertussis when a cough is present, whether to take prescribed medications, how to complete more preventive services, and how to understand the "new genetics", and family physician use of telehealth. (J Am Board Fam Med 2017;30:269-271.)

\section{Decision: Intensity of Depression Intervention}

The DOC- $6^{1}$ can help providers predict which patients with depression are likely to enter remission and which are likely to continue to suffer from persistent depressive symptoms after 6 months. This tool is based on demographic factors and familiar, commonly used instruments. The factors in the final instrument are intuitive and consistent with well-known literature, and most family physicians would be able to predict them. Advantages are that the instrument can be scored by office staff and is thus more straightforward than physician "intuition." Notably, this study was done in the setting of an established, reliable collaborative care model for patients with depression.

\section{Decision: When to Stop Colon Cancer Screening}

Physicians help patients make decisions about colon cancer screening (eg, when to stop screening). Comorbidities and life expectancy are important, but differences in viewpoints among specialties also are evident. Le et $\mathrm{al}^{2}$ report on the views of gastroenterologists versus primary care physicians regarding who takes responsibility to help patients make decisions to discontinue screening.

Conflict of interest: The authors are editors of the $7 A B F M$.

\section{Decision: Which Treatment for Localized Prostate Cancer}

Men diagnosed with localized prostate cancer face several treatment options with similar prognoses but substantial differences in side effects; therefore the decision can be confusing. Two studies show that significant gaps exist in patients' knowledge about localized prostate cancer treatment and outcomes, and that many men discuss the possibilities with their primary care providers. ${ }^{3,4}$ Do patients with more knowledge have an easier time making decisions regarding treatment for their prostate cancer? Do men who talk with their primary care provider make different treatment choices? The answers to these questions might surprise you. Important implications also exist for how family physicians assist their patients with newly diagnosed prostate cancer. ${ }^{5}$

\section{Decision: When to Consider and Test for Pertussis}

Ebell et $\mathrm{al}^{6}$ provide a wonderful review of the literature, analyzing the heterogeneity and likelihood of clinician impressions of various symptoms when making a clinical diagnosis of pertussis. Diagnosis remains challenging, particularly in adults, and relies heavily on a clinician's vigilance. Before current tests were widely available, I (MAB) once identified a middle-aged adult working in a nursing home with a probable diagnosis of pertussis. This prompted calls to the laboratory and the health department to determine how testing could be done; the test was positive and much more work to 
protect others ensued-a major outbreak of pertussis among adults was thus identified. Yes, pertussis has public health implications. This analysis is well worth the read.

\section{Decision: How and When to Use Telehealth in Family Medicine}

Telehealth is highly touted. Many readers probably have health insurance that encourages the use of telehealth, as health insurers now commonly encourage patients to engage in online visits with physicians. Further, Americans love their technology, with its convenience and immediacy. Some types of telehealth could be very helpful, such as teledermatology and telesupport for distant postoperative specialty care. Yet, telehealth remains a small part of health care overall. Moore et $\mathrm{al}^{7}$ report a nationwide survey, providing an update on family physicians' current provision of telehealth (low) and views of barriers. For family physicians to increase their provision of telehealth services, we would require (1) sufficient reimbursement dollars for it to be a good use of time, (2) reorganization of office and patient schedules, and (3) more evidence of how it efficiently improves health outcomes. Thus far, much telehealth is hype and is used as a marketing tool.

\section{Decision: Recognize the Real Reasons/Beliefs Behind Patient or Physician Adherence}

Beliefs about prescribed medicines and their effectiveness seem to be more important than other barriers to medication adherence. ${ }^{8}$ Thus, general questions such as, "What keeps you from taking the medicine?," "What would get you to take the medicine?," or "How do you feel about this medicine?" may assist in determining the real reasons people are not taking prescribed medications. This can lead to more productive adherence discussions. Similarly, family physician beliefs about a study intervention's value affected their participation in a multisite trial, over and above other common implementation barriers. ${ }^{9}$

\section{Decision: How to Promote Patient-Entered Data to Increase Preventive Services}

Foucher-Urcuyo and coauthors ${ }^{10}$ used a technology intervention-namely, patient-entered data using a tablet device in the waiting room-to increase the provision of preventive services. This method probably cues both patients and physicians to consider these services, and may be more successful than some other methods, such as getting patients to enter data from home, in advance of visits. It also may make the time in the waiting room go by more quickly.

\section{Decision: Use Medical Assistant Health Coaching for Lifestyle Change?}

In this pilot study, Djuric et $\mathrm{al}^{11}$ report positive weight-loss outcomes in the $49 \%$ of patients who completed 12 weeks of coaching. Overall, small differences were found at the end of the study. The health coaching focused on internal motivation and encouraged goal setting, and was sometimes delivered by telephone. Of note, the 2 medical assistants had bachelor's degrees, and the patients were well educated and exercised more than the average American at baseline.

\section{Decision: New Use for Dermoscopy}

Dermoscopy is gaining popularity among family physicians. Naimer ${ }^{12}$ alerts us to another innovative use of this versatile tool: facilitating the removal of cutaneous foreign bodies.

\section{The New Genetics}

Genetics knowledge is exploding, reducing the likelihood that most physicians will understand the latest implications and testing. Thus, we provide this brief overview from Milunsky ${ }^{13}$ to promote awareness of current genetic testing, including strengths and weaknesses.

\section{Primary Care Workforce}

It is widely accepted that (1) more family physicians are needed, (2) family physicians trained in community health centers are more likely to practice in similar settings, and (3) federal funding that supported additional residency positions in community health settings attracts trainees. However, the financing for the Teaching Health Center Graduate Medical Education program and its training positions are now in jeopardy, ${ }^{14}$ which is unfortunate and untimely for the health of the nation. We believe the Teaching Health Center Graduate Medical Education program is successful and should be continued and expanded. See also Gravel's (15) commentary on how funding instability limits the impact of Teaching Health Centers. 


\section{World Perspective on Primary Care}

The United States obviously is not ready to embrace and fulfill the promise of primary care the way other countries have. For example, by expanding primary care, Ecuador dramatically increased its international ranking for health care efficiency from 111th to 20th among 121 countries worldwide. ${ }^{16} \mathrm{We}$ wish that the United States understood the importance of primary care in reducing health care costs. In another article, Kao and $\mathrm{Wu}^{17}$ provide national-level data on the positive effect of continuity in ambulatory care on emergency department visits among the elderly in Taiwan. Another win for primary care!

To see this article online, please go to: http://jabfm.org/content/ 30/3/269.full.

\section{References}

1. Angstman KB, Garrison GM, Gonzalez CA, Cozine DW, Cozine EW, Katzelnick DJ. Prediction of primary care depression outcomes at six months: validation of DOC-6@. J Am Board Fam Med 2017;30: 281-7.

2. Le ST, Lash BR, Schroy PC III, Calderwood AH. Physician perceptions of surveillance follow-up colonoscopy in older adults. J Am Board Fam Med 2017;30: 371-3.

3. Daum LM, Reamer EN, Ruterbusch JJ, Liu J, Holmes-Rovner M, Xu J. Patient knowledge of and qualities of treatment decisions for localized prostate cancer. J Am Board Fam Med 2017;30:288-97.

4. Radhakrishnan A, Grande D, Ross M, et al. When primary care providers (PCPs) help patients choose prostate cancer treatment. J Am Board Fam Med 2017;30:298-307.

5. Jiang T, Stillson CH, Pollack CE, et al. How men with prostate cancer choose specialists: a qualitative study. J Am Board Fam Med 2017;30:220-9.

6. Ebell MH, Marchello C, Callahan M. Clinical diag- nosis of Bordetella pertussis infection: a systematic review. J Am Board Fam Med 2017;30:308-19.

7. Moore MA, Coffman M, Jetty A, Klink K, Petterson $\mathrm{S}$, Bazemore A. Family physicians report considerable interest in, but limited use of, telehealth services. J Am Board Fam Med 2017;30:320-30.

8. Gagnon MD, Waltermaurer E, Martin A, Friedenson C, Gayle E, Hauser DL. Patient beliefs have a greater impact than barriers on medication adherence in a community health center. J Am Board Fam Med 2017;30:331-6.

9. Balasubramanian BA, Heurtin-Roberts S, Krasny S, et al. Factors related to implementation and reach of a pragmatic multisite trial: the My Own Health Report (MOHR) study. J Am Board Fam Med 2017; 30:337-49.

10. Foucher-Urcuyo J, Longworth D, Roizen M, Hu B, Rothberg MB. Patient-entered wellness data and tailored electronic recommendations increase preventive care. J Am Board Fam Med 2017;30:350-61.

11. Djuric Z, Segar M, Orizondo C, et al. Delivery of health coaching by medical assistants in primary care. J Am Board Fam Med 2017;30:362-70.

12. Naimer SA. Therapeutic dermoscopy to facilitate detection and extraction of foreign bodies. J Am Board Fam Med 2017;30:374-6.

13. Milunsky A. The "new genetics" in clinical practice: a brief primer. J Am Board Fam Med 2017;30:377-9.

14. Kurz T, Liaw W, Wingrove P, Petterson S, Bazemore A. Funding instability reduces the impact of the federal Teaching Health Center Graduate Medical Education program. J Am Board Fam Med 2017; 30:279-80.

15. Gravel J, Jr. Uncertainty in Teaching Health Center (THC) Funding: Still Crazy After All These Years. J Am Board Fam Med 2017;30:275-8.

16. Aldulaimi S, Mora FE. A primary care system to improve health care efficiency: lessons from Ecuador. J Am Board Fam Med 2017;30:380-3.

17. Kao Y-H, Wu S-C. Effect of continuity of care on emergency department use in elderly patients with asthma in Taiwan. J Am Board Fam Med 2017;30: 384-95. 